\title{
Sternal puncture allows an early diagnosis of poststernotomy mediastinitis
}

\author{
Sidney Benlolo, MDa \\ Joaquim Matéo, $\mathrm{MD}^{\mathrm{a}}$ \\ Laurent Raskine, $M D^{\mathrm{b}}$ \\ Omar Tibourtine, $\mathrm{MD}^{\mathrm{a}}$ \\ Alain Bel, $\mathrm{MD}^{\mathrm{C}}$ \\ Didier Payen, MD, PhD \\ Alexandre Mebazaa, MD, $\mathrm{PhD}^{\mathrm{a}}$
}

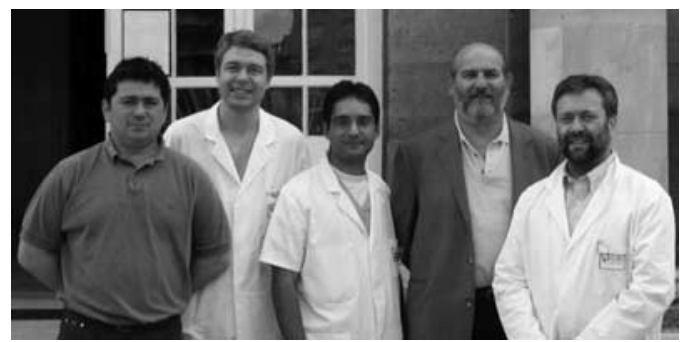

Matéo, Mebazaa, Benlolo, Payen, Raskine (left to right)
Objectives: Poststernotomy mediastinitis after cardiac operations is a nosocomial infection involving the mediastinal space and the sternum, with a high mortality rate mostly related to a late diagnosis. We investigated whether sternal puncture might facilitate and shorten the delay in the diagnosis of mediastinitis.

Methods: Of 1024 patients undergoing sternotomy for cardiac surgery, sternal puncture was performed in a subgroup of 49 patients in whom mediastinitis was suspected.

Results: Sternal puncture culture results were positive for all patients with true mediastinitis $(n=23)$ and negative in 24 of 26 patients without mediastinitis. In addition, sternal puncture allowed diagnosis of mediastinitis with a shorter delay ( $9 \pm 5$ days vs $13 \pm 8$ days, $P=.04)$ and caused a reduction in the length of mechanical ventilation ( $3 \pm 4$ days vs $10 \pm 13$ days, $P=.02)$ and stay in the intensive care unit $(9 \pm 7$ days vs $18 \pm 15$ days, $P=.02)$ compared with that found in another group of patients $(n=20)$ operated on for true mediastinitis on the basis of the presence of classic, delayed, clinical signs.

From the Department of Anesthesiology and Critical Care Medicine ${ }^{\mathrm{a}}$; Service de Bactériologie et de Virologie, ${ }^{\mathrm{b}}$ Institut Fédératif de Recherches Circulation, Hôpital Lariboisière; Service de Chirurgie CardioVasculaire B, ${ }^{\mathrm{c}}$ Hôpital Bichat-Claude Bernard; Assistance Publique-Hôpitaux de Paris, France.

This study was supported by a grant from Ministère Français de l'Enseignement Supérieur et de la Recherche.

Received for publication Jan 25, 2002; revisions requested April 8, 2002; revisions received June 25, 2002; accepted for publication July 2, 2002

Address for reprints: Alexandre Mebazaa, MD, PhD, Département d'Anesthésie-Réanimation-SMUR, Hôpital Lariboisière, 2 rue Ambroise-Paré, 75475 Paris Cedex 10, France (E-mail: alexandre.mebazaa@1rb. ap-hop-paris.fr).

J Thorac Cardiovasc Surg 2003;125:611-7

Copyright (C) 2003 by The American Association for Thoracic Surgery

$0022-5223 / 2003 \$ 30.00+0$

doi: $10.1067 / \mathrm{mtc} .2003 .164$
Conclusions: Our study shows that sternal puncture is a rapid and safe method to ensure the diagnosis of poststernotomy mediastinitis.

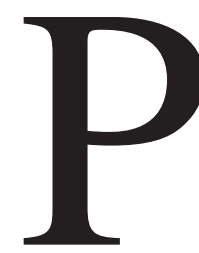

oststernotomy mediastinitis is a nosocomial infection involving the mediastinal space and the sternum (sternitis). ${ }^{1}$ It can be clinically obvious or obscure..$^{2-4}$ Indeed, classic signs, including wound drainage and sternal instability, are frequent ${ }^{4-6}$ but not specific for underlying infection $^{6,7}$ and are late signs of mediastinal infection. ${ }^{2,4,7} \mathrm{~A}$ few tests, including computed tomographic scanning and epicardial wire (EW) culture, have been examined for their ability to help in the early diagnosis of poststernotomy mediastinitis, but results have been inconclusive. ${ }^{8,9}$ Furthermore, aspiration of the anterior mediastinal space was performed more than 15 years ago but was not pursued because of the potential risk for heart injury, large vessel injury, or both in inexperienced hands. ${ }^{10}$

To facilitate the diagnosis of poststernotomy mediastinitis, we prospectively evaluated the sternal puncture, in which bacteriologic samples are taken between the sternal edges rather than from the mediastinal space, assuming that sternitis is consistently present in all cases of postoperative mediastinitis.

\section{Patients and Methods}

A prospective study was performed from February 1996 to September 1999 in 1024 patients undergoing sternotomy in the cardiac surgery unit of our institution (Figure 1). The ethical 


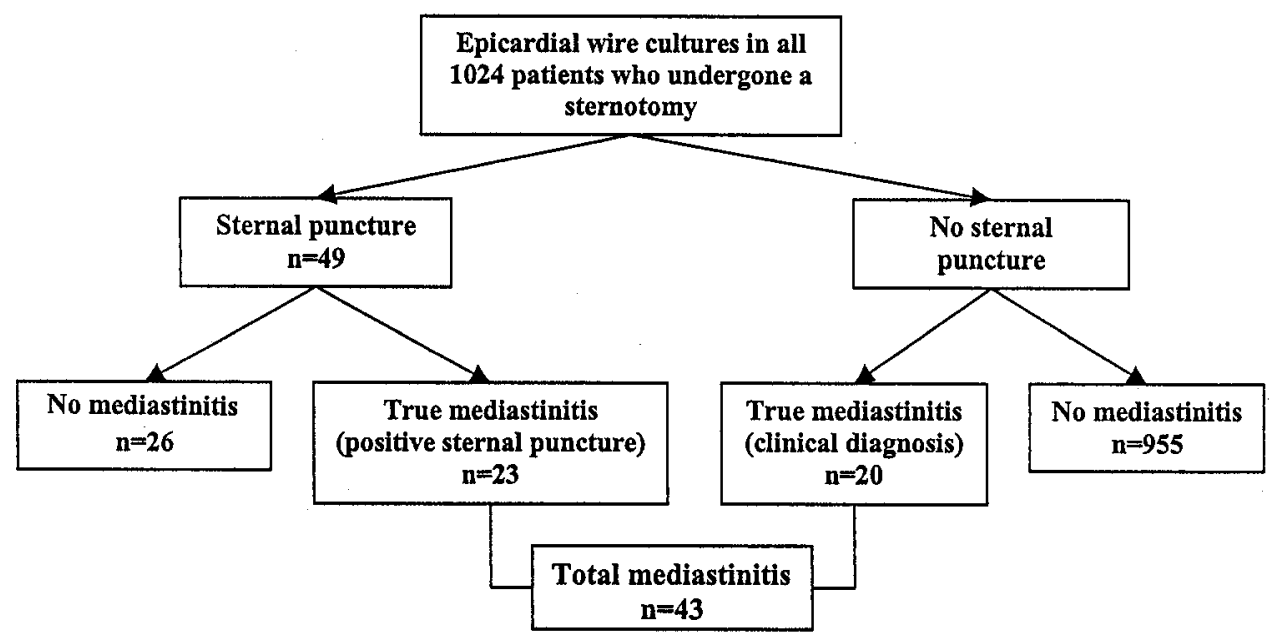

Figure 1. Study design. Sternal puncture was performed on patients when poststernotomy mediastinitis was suspected (see the "Methods" section).

committee of our institution (Comité Consultatif de Protection des Personnes se prêtant à des Recherches Biomédicales of SaintLouis University Hospital) approved this study and waived the need for informed consent.

\section{Definition of Poststernotomy Mediastinitis}

True mediastinal wound infection (or mediastinitis) has been previously described as clinical or microbiologic evidence of sternitis with or without mediastinal sepsis and requiring surgical debridement. ${ }^{1}$ In our study true mediastinitis (ie, deep wound infection) was always confirmed by means of culture of samples obtained during surgical exploration. Infections restricted to the subcutaneous tissue, as well as mechanical sternal dehiscence, were excluded (see below). In addition, because mediastinitis is mostly seen between 4 and 30 days after an operation, ${ }^{5}$ the lack of mediastinitis was based on a 3-month follow-up of patients who did not have clinical signs of mediastinitis and had no need of further reintervention.

\section{EW Cultures}

EWs were systematically put in place during cardiac surgery and were mostly removed 6 to 7 days later unless heart pacing was still necessary. The wire's distal $2 \mathrm{~cm}$ were taken under sterile conditions and placed in a tube containing $1 \mathrm{~mL}$ of meat liver dextrose broth, and EW samples were cultured by using a semiquantitative method. Briefly, $50 \mathrm{~mL}$ of the broth was cultured onto aerobic and anaerobic blood agar plates. The plates were incubated at $37^{\circ} \mathrm{C}$ and inspected for microbial growth daily for 3 days. All microbial organisms obtained from cultures were identified, and their susceptibilities were established.

Sternal Puncture: Technique and Criteria of Inclusion After the immediate postoperative period, patients remained either in a ward of the Department of Cardiac Surgery or were transferred to the Department of Cardiology or Medicine of our institution.
In the patients who remained in a ward of the Department of Cardiac Surgery, sternal puncture was performed when local signs of sternal wound infection (inflammatory wound, wound drainage, and sternal instability), signs of sepsis, or both appeared on the basis of the following criteria ${ }^{11}$ : (1) body temperature of greater than $38.5^{\circ} \mathrm{C}$ or less than $35.5^{\circ} \mathrm{C}$; (2) heart rate of greater than 90 beats/min; (3) white blood cell count of greater than $12,000 / \mathrm{mm}^{3}$ or less than $4000 / \mathrm{mm}^{3}$; or (4) tachypnea (respiratory rate $>20$ breaths/min or mechanical ventilation) $n=49$ patients. Sternal puncture was performed with 21-gauge hypodermic needles (Microlance TM 3, Becton Dickinson) and 10-mL syringes (Figure 2). After skin preparation with polyvidone-iodine, the needle was introduced between the 2 sternal edges approximately $1 \mathrm{~cm}$ in depth, at the level of spongy bone. No suction was applied while introducing the needle from the skin to the sternal edges of the sternotomy to differentiate superficial infection from deep wound infection. Suction was only started when the needle could be introduced between the 2 sternal edges. Sternal punctures were repeated, with different needles at 3 levels (upper, middle, and lower) of the sternotomy. If the fluid volume collected from the sternal space was smaller than $1 \mathrm{~mL}$, it was diluted with $1 \mathrm{~mL}$ of sterile saline solution. Samples were promptly delivered to the microbiological laboratory for Gram staining and cultures onto both aerobic and anaerobic agar plates, as described above for the EW cultures. In 23 of 49 patients, surgical debridement was performed on the basis of the positive bacteriologic test results (Gram staining, culture, or both, including the presence of coagulase-negative Staphylococcus epidermidis ${ }^{2,9,12}$ ) of at least one of the sternal punctures (Figure 1). Of note, when culture of a sternal puncture sample revealed Propionobacterium acnes or coagulasenegative Staphylococcus species other than S epidermidis, this was considered as skin contamination, and sternal puncture was repeated 24 hours later.

When patients were hospitalized in other wards than the Department of Cardiac Surgery, they were referred back to us for surgical debridement on the basis of classic clinical signs, bacte- 

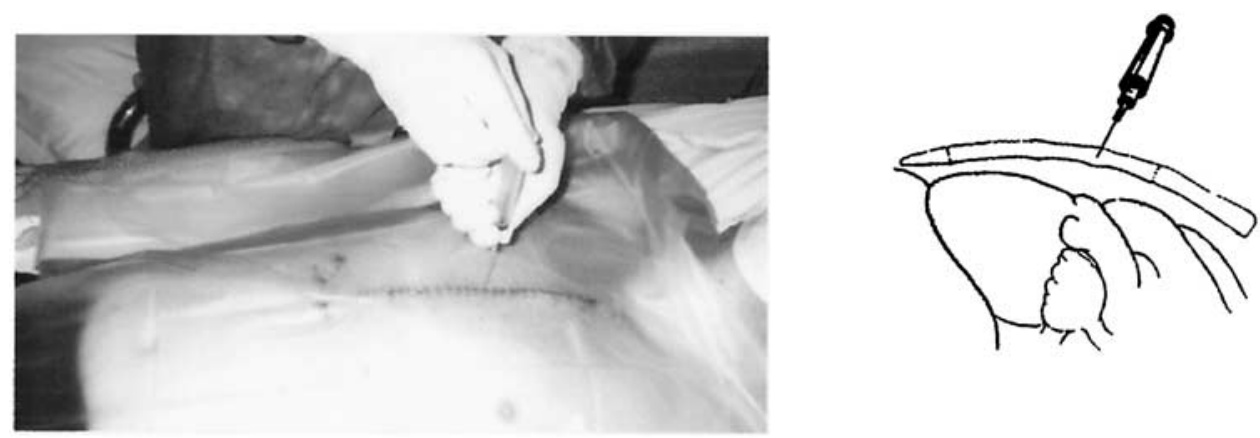

Figure 2. Technique of sternal puncture. The needle was introduced between the 2 sternal edges at the level of spongy bone. The picture shows a sternal puncture performed in the middle portion of the sternotomy. During the same procedure, sternal punctures were repeated at the upper and lower portions of the sternotomy, with different needles.

riologic signs, or both strongly suggesting poststernotomy mediastinitis: wound instability, septic shock, or both ${ }^{11}$ associated or not with positive results on EW or blood cultures. ${ }^{12}$ In these patients surgical debridement was performed on an urgent basis, as previously described, ${ }^{12}$ without sternal puncture $(n=20$, Figure $1)$.

\section{Analysis of Bacteriologic Data}

Bacteriologic results of sternal puncture and EWs were considered as true positive when organisms cultured were the same as and had identical antibiotic susceptibility as those found during surgical intervention. Results were available within 1 hour for Gram staining, and cultures were inspected daily for 3 days, as described elsewhere.

\section{Surgical and Intensive Care Unit Management of Mediastinitis}

All patients with true mediastinitis underwent reoperation after achievement of general anesthesia, according to the same surgical debridement procedure: removal of all necrotic tissues (infected tissues were sent to the bacteriologic laboratory), curettage of the sternal edges until fresh bone blood was obtained, repeated irrigation with polyvidone-iodine solution, and wound drainage with the closed technique, with Redon catheters connected to vacuum bottles. ${ }^{13,14}$ Intravenous antibiotics were started immediately before anesthesia for surgical debridement and always after sternal puncture. Antibiotic therapy was either initially guided by preoperative bacterial investigations (eg, sternal puncture, EW culture, positive blood culture results, and Staphylococcus species nasal carriage) or, in the absence of positive culture results, on the basis of probabilistic antistaphylococcal therapy, combining vancomycin with fucidic acid. Antibiotic therapy was rapidly adapted according to the antibiogram of bacteria found during surgical intervention and continued for an average of at least 6 weeks after the operation (4 weeks of intravenous therapy with 2 antibiotics, followed by 2 weeks orally with 1 antibiotic).

\section{Outcome of Patients After Surgical Debridement}

After surgical debridement, outcome (eg, mortality rate, length of mechanical ventilation, and length of intensive care unit [ICU] stay) was compared in patients with true mediastinitis diagnosed by means of sternal puncture and those in whom diagnosis was based on the presence of classic clinical signs. ${ }^{12}$ The severity of illness score was assessed at the day of the operation by using the Simplified Acute Physiology Score (SAPS II). ${ }^{15}$

\section{Statistical Analysis}

Data are presented as means \pm SD. All data collected were stored in a computer, and we used Excel 97 (Microsoft) and Statview 5 (SAS Institute) software for statistical analysis.

Quantitative values were compared by using the unpaired Student $t$ test and the Mann-Whitney $U$ test when modal distribution was not observed. Nominal variables were analyzed by using the $\chi^{2}$ test with the Yates correction if necessary.

\section{Results}

During the study period (42 months), we followed 1024 adult patients who had undergone a median sternotomy for cardiac surgery in our institution. Among these patients, the mediastinitis rate was $4.2 \%(\mathrm{n}=43)$, and the mortality rate of those with mediastinitis was $21 \%(n=9 / 43)$.

When compared with the bacteria found during operations of patients with true mediastinitis, EW culture showed a high rate of false-positive (69/84) and false-negative (28/ 43) results (Table 1).

\section{Sternal Puncture Cultures}

Forty-nine patients underwent sternal puncture for suspicion of poststernotomy mediastinitis while they were hospitalized in the ward of the Department of Cardiac Surgery (see the "Methods" section). All patients undergoing puncture had at least 2 signs of systemic inflammation (Table 2).

Sternal puncture (at least one) was technically possible in all 49 patients. It allowed the diagnosis of postoperative mediastinitis in 23 patients on the basis of the culture findings (mostly Staphylococcus species, Table 3) that were identical in the sternal puncture and in samples obtained during surgical intervention. When compared with the bac- 
TABLE 1. Results of EW cultures, sternal puncture Gram stains, and sternal puncture cultures

\begin{tabular}{lccr}
\hline & $\begin{array}{c}\text { True } \\
\text { mediastinitis }\end{array}$ & $\begin{array}{c}\text { No } \\
\text { mediastinitis }\end{array}$ & Total \\
\hline EW & & & \\
Positive & 15 & 69 & 84 \\
Negative & 28 & 912 & 940 \\
Total & 43 & 981 & 1024 \\
Sternal puncture & Gram stains & & \\
Positive & 12 & 0 & 12 \\
Negative & 11 & 26 & 37 \\
Total & 23 & 26 & 49 \\
Sternal puncture cultures & 23 & & \\
Positive & 0 & 2 & 25 \\
Negative & 23 & 24 & 24 \\
Total & 26 & 49 \\
\hline
\end{tabular}

Results were considered as true positive when bacterial findings were identical to samples obtained during surgical intervention.

TABLE 2. Main characteristics of patients in whom a sternal puncture was performed

\begin{tabular}{lc}
\hline $\mathrm{n}$ & 49 \\
Age (y) & $65 \pm 11$ \\
Male/female sex & $33 / 16$ \\
Initial operation (\%) & 45 \\
$\quad$ Coronary bypass & 37 \\
Valve replacement & 8 \\
Combined coronary bypass and valve & \\
replacement & 10 \\
Other & \\
Criteria for sternal puncture (\%) & \\
Systemic signs & 61 \\
Temperature $>38^{\circ} \mathrm{C}$ & 81 \\
$\quad$ WBC $>12,000$ or $<4000$ & 26 \\
Positive blood culture result & 30 \\
Systolic arterial pressure $<90 \mathrm{~mm} \mathrm{Hg}$ & 16 \\
$\quad$ Oliguria & 20 \\
Lactate $>2$ mmol/L & \\
Local signs & 43 \\
Inflammatory wound drainage & 18 \\
$\quad$ Wound instability &
\end{tabular}

This includes patients with mediastinitis $(n=23)$ who had greater local signs (inflammatory wound drainage, 74\%; wound instability, 30\%) than those without mediastinitis (inflammatory wound drainage, 19\%; wound instability, 7\%). As previously described, 1,2,4,10 the presence of local signs gave a high index of suspicion of mediastinitis but was not specific.

teria found during the operation, Gram stain results of sternal puncture show 12 of 23 true-positive and no falsepositive results (Table 1). Bacteriologic results of sternal puncture were further improved with cultures, mostly received 24 hours later (23/23 true-positive results; Table 1). In the group of patients without mediastinitis undergoing sternal puncture $(\mathrm{n}=26), 24$ had true-negative cultured sternal puncture results, and 2 were considered to have false-positive results (Table 1) because bacteria found in the sternal puncture were Propionobacterium acnes and coagulase-negative Staphylococcus species other than S epidermidis. These 2 patients were, however, not operated on because of suspicion of skin contamination. A second puncture performed 24 hours later had negative results for both patients, and 3-month follow-up confirmed the lack of mediastinitis.

\section{Clinical Observations in Patients Undergoing Sternal Puncture}

According to the bacteriologic results described above, 12 patients undergoing sternal puncture of the 23 with true mediastinitis were operated on the day of sternal puncture on the basis of positive Gram stain results. The remaining 11 patients were operated on 24 hours later at the time the results of sternal puncture cultures were given.

For the other 26 patients undergoing sternal puncture in whom diagnosis of mediastinitis was not confirmed by means of bacteriologic tests (including the 2 patients considered as having false-positive results), further explorations showed postoperative complications other than mediastinitis, such as acute lung injury $(\mathrm{n}=10)$, cardiogenic shock $(n=9)$, superficial wound infection $(n=2)$, catheter infection $(\mathrm{n}=2)$, isolated fever $(\mathrm{n}=2)$, and pyelonephritis $(\mathrm{n}=1)$. The lack of subsequent mediastinitis was confirmed at the 3-month clinical follow-up (see the "Methods" section).

\section{Postoperative Follow-up}

Clinical characteristics and outcomes were compared between the group of 23 patients with true mediastinitis diagnosed by means of sternal puncture (described above) and another group of 20 patients transferred to the Department of Cardiac Surgery with a strong suspicion of poststernotomy mediastinitis on the basis of the classic combination of clinical signs (ie, wound instability or inflammatory wound $[\mathrm{n}=19]$, fever $[\mathrm{n}=9]$, and/or hypotension $[\mathrm{n}=8]$ ) and bacteriologic signs (ie, positive blood culture results $[\mathrm{n}=5]$ and positive EW culture results $[n=5])$. In the face of strong signs of mediastinitis, these 20 patients were operated on an urgent basis, as previously described, ${ }^{9}$ and no sternal puncture was performed. Surgical and bacteriologic findings subsequently confirmed true poststernotomy mediastinitis in all 20 patients.

Table 3 shows that, despite similar clinical and bacteriologic characteristics, several items have been improved in patients undergoing sternal puncture, including a shorter delay between the initial cardiac surgery and the diagnosis of mediastinitis $(9 \pm 5$ days vs $13 \pm 8$ days with and without sternal puncture, respectively; $P=.04$ ) and a lower SAPS II score at the day of surgical debridement. Table 3 also shows a shorter length of mechanical ventilation in the patients undergoing sternal puncture than in the patients not 
TABLE 3. Comparison of the postoperative course of patients in whom true mediastinitis was diagnosed with sternal puncture versus those in whom diagnosis was based on the presence of classic clinical signs

\begin{tabular}{|c|c|c|c|}
\hline & $\begin{array}{c}\text { True mediastinitis } \\
\text { diagnosed by means of } \\
\text { positive sternal puncture }\end{array}$ & $\begin{array}{c}\text { True mediastinitis } \\
\text { diagnosed by means of } \\
\text { the presence of classic } \\
\text { clinical signs }\end{array}$ & $\begin{array}{c}P \\
\text { value }\end{array}$ \\
\hline No. of patients & 23 & 20 & \\
\hline Age $(y)$ & $67 \pm 10$ & $66 \pm 9$ & NS \\
\hline Male/female sex & $15 / 8$ & $15 / 5$ & NS \\
\hline \multicolumn{4}{|l|}{ Comorbidities } \\
\hline COPD (\%) & 21 & 35 & NS \\
\hline Diabetes $(\%)$ & 30 & 45 & NS \\
\hline Obesity $(\%)$ & 43 & 35 & NS \\
\hline $\operatorname{LVEF}(\%)$ & $49 \pm 9$ & $45 \pm 11$ & NS \\
\hline \multicolumn{4}{|l|}{ Initial operation (\%) } \\
\hline Coronary bypass & 52 & 75 & NS \\
\hline Valve replacement & 40 & 5 & NS \\
\hline $\begin{array}{l}\text { Combined coronary bypass and } \\
\text { valve replacement }\end{array}$ & 8 & 20 & NS \\
\hline \multicolumn{4}{|l|}{ Bacteria $(\mathrm{n})$} \\
\hline Staphylococcus aureus & 6 & 8 & \\
\hline Staphylococcus epidermidis & 5 & 2 & \\
\hline Enterococcus faecalis & 2 & 3 & \\
\hline Klebsiella pneumoniae & 3 & 2 & \\
\hline Others & 7 & 5 & \\
\hline $\begin{array}{l}\text { Delay between initial cardiac surgery } \\
\text { and the diagnosis of mediastinitis (d) }\end{array}$ & $9 \pm 5$ & $13 \pm 8$ & .04 \\
\hline \multicolumn{4}{|l|}{ Postoperative course in ICU } \\
\hline SAPS II score* & $22 \pm 13$ & $40 \pm 13$ & .0001 \\
\hline Mortality (n) & 5 & 4 & NS \\
\hline Length of mechanical ventilation (d) & $3 \pm 4$ & $10 \pm 13$ & .02 \\
\hline Delay for mediastinal sterilization (d) & $16 \pm 12$ & $14 \pm 6$ & NS \\
\hline Primary debridement failure (n) & 1 & 2 & NS \\
\hline Discharge from ICU (d) & $9 \pm 7$ & $18 \pm 15$ & .02 \\
\hline
\end{tabular}

Data are expressed as means \pm SD. Of note, no operations other than coronary bypass, valve replacement, or combined coronary bypass and valve replacement were performed in these patients. NS, Not significant; COPD, chronic obstructive pulmonary disease; $L V E F$, left ventricular ejection fraction.

undergoing sternal puncture $(3 \pm 4$ days vs $10 \pm 13$ days, $P=.02$ ). This allowed a shorter stay in the ICU and an earlier transfer to the ward of the Department of Cardiac Surgery, even with mediastinal Redon catheters, which were monitored in the ward with the same protocol as in the ICU. However, despite an obvious improvement in morbidity, mortality remained similar in both groups, with no differences in the cause of death. Among the 9 patients that died after mediastinitis, 4 died in the first days $(<4$ d) after the operation because of major bleeding from coronary graft anastomosis $(\mathrm{n}=2)$ or multiple organ failure directly related to mediastinitis $(\mathrm{n}=2)$. The 5 other patients died later (8-26 days) from aortic complications (bleeding or dissection) or multiple organ failure related to sources of infection other than the sternum or mediastinum (endocarditis, ischemic colon, and lung infection).

\section{Discussion}

This study evaluated EW cultures and sternal puncture in the diagnosis of true poststernotomy mediastinitis. It con- firmed that EW cultures had a high rate of false-positive results, as previously published. ${ }^{9}$ In addition, our study showed, for the first time, that rates of both true-positive and true-negative results reached $100 \%$ when using sternal puncture for the diagnosis of true mediastinitis. Furthermore, sternal puncture permitted an early diagnosis and shortened the length of both mechanical ventilation and ICU stay.

\section{Sternal Puncture in the Diagnosis of Poststernotomy Mediastinitis}

Few bacteriologic procedures aimed at obtaining samples from the anterior mediastinum have been previously described. This includes retrosternal aspiration through the sternotomy ${ }^{3}$ and subxiphoid retrosternal aspiration. ${ }^{10}$ However, the major risks of these 2 methods are injuries to epicardial vessels, vascular grafts, or the cardiac wall.

To safely obtain samples from the infected area, we have developed a sternal puncture procedure that consists of sampling material between the 2 edges of the sternum for 
bacteriologic analysis (Figure 2). Sternal puncture was based on the hypothesis that infection of the mediastinal anterior space after cardiac surgery was consistently associated with a sternal osteomyelitis (sternitis). Indeed, some authors have previously postulated that the median sternotomy wound infection started at a localized area of sternal osteomyelitis, with minimal external signs similar to early osteomyelitis in other bones. ${ }^{1-3}$

In our study sternal puncture was performed in 49 patients with a clinical suspicion of mediastinitis. In 23 patients the bacteriologic results of sternal puncture were positive, indicating the need for surgical debridement. Patients with a positive Gram stain result underwent operations on the day of the puncture procedure $(\mathrm{n}=12)$, and the other patients $(\mathrm{n}=11)$ were operated on 24 hours later, when culture results were available. Interestingly, the bacteriologic results of the material obtained by means of both the sternal puncture and surgical debridement support the hypothesis of sternal osteomyelitis as a starting point of mediastinitis. Indeed, all 23 patients undergoing sternal puncture with true mediastinitis had both a positive sternal puncture result and sternitis confirmed during the debridement procedure. By contrast, Gram stain and culture results were negative for the 26 remaining patients (except for 2 patients who had a skin contamination) in whom the lack of sternitis and mediastinitis was confirmed by means of 3-month follow-up. The latter result also strongly favors sternal puncture as a safe procedure that did not contaminate sternal bone from the "infected" superficial area in these 26 patients.

\section{Sternal Puncture and Clinical Outcome of Poststernotomy Mediastinitis}

A comparison of the patients with true mediastinitis given a diagnosis of sternal puncture and those in whom the diagnosis was made in the classic manner (on the basis of the presence of mixed clinical and bacteriologic signs) showed that sternal puncture allowed an early diagnosis of mediastinitis: $9 \pm 5$ days versus $13 \pm 8$ days in our study or roughly 15 days in previously published articles $3,9,12,14,16,17$ by using the classic means of diagnosis. Although classic symptoms of wound infection, such as drainage or sternal instability, are usually the clinical findings leading to the diagnosis of mediastinitis, they usually represent advanced degrees of mediastinal infection. ${ }^{10}$ By contrast, our strategy was to consider any clinical abnormality after cardiac surgery as a potential sign of early mediastinitis and then an indication to perform sternal puncture. This approach allowed a rapid diagnosis of mediastinitis and subsequently improved the clinical outcome of patients with mediastinitis, lowering the SAPS II score and shortening the ICU stay, and was helpful in the differential diagnosis of postoperative complications after cardiac surgery. Despite the reduction of the delay in diagnosis and an improvement in global outcome, no reduction in mortality could be observed. One should mention, however, that 7 of 9 deceased patients died from a cause that was not directly related to mediastinitis. In addition, the number of studied patients was likely too small to expect a decrease in mortality. Furthermore, other surgical approaches, including placement of bilateral pectoralis major advancement flaps ${ }^{16}$ or vacuum-assisted closure, ${ }^{17}$ might have improved the survival rate. Accordingly, further multicentric studies are needed to evaluate the effect of sternal puncture on the overall mortality.

In summary, poststernotomy mediastinitis is a severe nosocomial infection for which a surgical treatment must be promptly performed. Accordingly, all means facilitating an early diagnosis should be used, but only those that allow microbiologic analysis of the mediastinum can give strong arguments in favor of a specific mediastinal infectious process. $^{2}$ We have developed a sternal puncture procedure that consists of sampling material from the sternal space for bacteriologic analysis. Rates of both true-positive and truenegative results reached $100 \%$, with no adverse effects related to the sternal puncture. Sternal puncture allowed a reduction in the delay of the diagnosis of poststernotomy mediastinitis, therefore improving global clinical outcome (length of ICU stay and length of mechanical ventilation) but without a change in the overall mortality rate.

We thank Ghylaisne Perez and Emmanuelle Florens for helping to manage patients; Phillipe Menasché, Peter Karpati, and AnneClaire Lukascewicz for editing the article; and Christine Berton for statistical expertise. In addition, we thank the nursing staff of the cardiosurgical and RPOT units.

\section{References}

1. El Oakley RM, Wright JE. Postoperative mediastinitis: classification and management. Ann Thorac Surg. 1996;61:1030-6.

2. Grossi EA, Culliford AT, Krieger KH, Kloth D, Press R, Baumann FG, et al. A survey of 77 major infectious complications of median sternotomy: a review of 7,949 consecutive operative procedures. Ann Thorac Surg. 1985;40:214-23.

3. Culliford AT, Cunningham JN Jr, Zeff RH, Isom OW, Teiko P, Spencer FC. Sternal and costochondral infections following openheart surgery. J Thorac Cardiovasc Surg. 1976;72:714-25.

4. Jimenez-Martinez M, Arguero-Sanchez R, Perez-Alvarez JJ, MinaCastaneda P. Anterior mediastinitis as a complication of median sternotomy incisions: diagnostic and surgical considerations. Surgery. 1970;67:929-34.

5. Sarr MG, Gott VL, Townsend TR. Mediastinal infection after cardiac surgery. Ann Thorac Surg. 1984;38:415-26.

6. Kay HR, Goodman LR, Teplick SK, Mundth ED. Use of computed tomography to assess mediastinal complication after median sternotomy. Ann Thorac Surg. 1983;36:706-14.

7. Engelman RM, Williams CD, Gouge TH, Chase RM Jr, Falk EA, Boyd AD, et al. Mediastinitis following open-heart surgery. Review of two years' experience. Arch Surg. 1973;107:772-8.

8. Misawa Y, Fuse K, Hasegawa T. Infectious mediastinitis after cardiac operations: computed tomographic findings. Ann Thorac Surg. 1998; 65:622-4.

9. Maroto LC, Aguado JM, Carrascal Y, Perez A, Perez-de-la-Sota E, Cortina JM, et al. Role of epicardial pacing wire cultures in the diagnosis of poststernotomy mediastinitis. Clin Infect Dis. 1997;24: $419-21$. 
10. Sarr MG, Watkins L Jr, Stewart JR. Mediastinal tap as useful method for the early diagnosis of mediastinal infection. Surg Gynecol Obstet. 1984;159:79-81.

11. Bone RC, Balk RA, Cerra FB, Dellinger RP, Fein AM, Knaus WA, et al. Definitions for sepsis and organ failure and guidelines for the use of innovative therapies in sepsis. The ACCP/SCCM Consensus Conference Committee. American College of Chest Physicians/Society of Critical Care Medicine. Chest. 1992;101:1644-55.

12. Kirsch M, Mekontso-Dessap A, Houël R, Giroud E, Hillion ML, Loisance DY. Closed drainage using redon catheters for poststernotomy mediastinitis: results and risk factors for adverse outcome. Ann Thorac Surg. 2001;71:1580-6.

13. Durandy Y, Batisse A, Bourel P, Dibie A, Lemoine G, Lecompte Y. Mediastinal infection after cardiac operation. A simple closed technique. J Thorac Cardiovasc Surg. 1989;97:282-5.
14. Calvat S, Trouillet JL, Nataf P, Vuagnat A, Chastre J, Gibert C. Closed drainage using Redon catheters for local treatment of poststernotomy mediastinitis. Ann Thorac Surg. 1996;61:195201.

15. Le Gall JR, Lemeshow S, Saulnier F. A new Simplified Acute Physiology Score (SAPS II) based on a European/North American multicenter study. JAMA. 1993;270:2957-63.

16. El Gamel A, Yonan NA, Hassan R, Jones MT, Campbell CS, Deiraniya AK, et al. Treatment of mediastinitis: early modified Robicsek closure and pectoralis major advancement flaps. Ann Thorac Surg. 1998;65:41-7.

17. Gustafsson R, Johnsson P, Algotsson L, Blomquist S, Ingemansson R. Vacuum-assisted closure therapy guided by $\mathrm{C}$-reactive protein level in patients with deep sternal wound infection. J Thorac Cardiovasc Surg. 2002;123:895-900.

\section{Authoritative}

The Journal of Thoracic and Cardiovascular Surgery is the most frequently cited thoracic/cardiovascular surgery journal in the Science Citation Index. An article in JTCVS is cited on average almost twice as often as those in the closest cardiothoracic journal. 